\title{
Cost of morphological specialization: feeding performance of the two morphs in the trophically polymorphic cichlid fish, Cichlasoma citrinellum
}

\author{
A. Meyer* \\ Museum of Vertebrate Zoology, and Department of Zoology, University of California, Berkeley, CA 94720, USA
}

\begin{abstract}
Summary. The feeding performance on soft and hard prey of two morphs of the trophically polymorphic Neotropical cichlid fish, Cichlasoma citrinellum, was investigated in the laboratory. The molariform morphs, specialized to feed on hard prey, are able to crack snail shells that are twice as hard as those cracked by the papilliform morphs. During ecological bottlenecks in food resources this ability should allow molariform morphs to exploit alternate, less preferred prey sources that are not available to papilliform morphs. Analysis of stomach contents revealed that molariform morphs feed significantly more often on hard snails than do papilliform morphs (Meyer 1989a). The performance advantage of the trophically specialized morphs when feeding on hard prey is countered by their less efficient performance on soft diets. The morphologically generalized papilliform morph feeds more efficiently on soft prey. The abundance of preferred soft prey, seasonal fluctuations in prey availability and the frequency of ecological bottlenecks may determine the relative abundance of these two morphs in natural populations in Nicaraguan lakes.
\end{abstract}

Key words: Trophic polymorphism - Morphological adaptation - Cost of specialization - Molluscivorous cichlids

Ecomorphologists believe that the trophic morphology of fishes mirrors the feeding mode and possibly the type of prey that is preferred by a particular species (e.g. Keast and Webb 1966; Gatz 1979; van Oijen 1982; Hoogerhoud et al. 1983; Barel 1983; Wainwright 1987, 1988). Resource partitioning in fishes is believed to be due to functional morphological constraints on prey choice (Werner 1977; Liem 1984; Wainwright 1988). However, data on morphological constraints on the exploitation of trophic resources in fishes are rarely gathered (Wainwright 1987, 1988). Yet, it has long been thought that morphological differences between species may be instrumental to our understanding of resource utilization, ecological community structure and ultimately the process of speciation (e.g. Van Valen 1965; Grant 1986).

Cichlid fishes belong to the perciform suborder Labroidei (Kaufman and Liem 1982). These fishes have radiated greatly and comprise some of the most species rich families

Konstanzer Online-Publikations-System (KOPS) URL: http://www.ub.uni-konstanz.de/kops/volltexte/2007/3685/ URN: http://nbn-resolving.de/urn:nbn:de:bsz:352-opus-36851 of vertebrates. All fishes of this suborder possess a modified pharyngeal jaw apparatus. Liem (1973) proposed that this morphological novelty, coupled with the functional versatility of cichlids, is responsible for their high taxonomic diversity and their occupation of very narrow ecological niches. The pharyngeal jaws bear a highly specialized dentition which, in conjunction with modified branchial musculature, facilitates the manipulation of prey. Pharyngeal jaws allow the processing of types of prey that cannot be handled as successfully by oral jaws (Slootweg 1987). The evolution of this morphological novelty may have facilitated independent morphological specializations of these two sets of jaws and led to the ecological and taxonomic diversification of this group of fishes. Yet, the family Embiotocidae is comprised of only few species, although they also possess pharyngeal jaws (Liem 1984).

Morphological differences between species of cichlids are small; they are morphologically highly specialized, particularly with respect to trophic structure (e.g. Hoogerhoud 1984; reviewed in Meyer 1987). The finding that some cichlid species are phenotypically plastic in their head morphology (Meyer 1987) and others are polymorphic in the structure of their pharyngeal jaws, has received wide attention because these phenomena have bearing on our understanding of sympatric speciation and adaptive radiations.

\section{Evolutionary significance of trophic polymorphisms in cichlids}

Trophically polymorphic cichlids have been found in Africa (Astatoreochromis alluaudi, Greenwood 1965) and in the Neotropics (Cichlasoma minckleyi, Sage and Selander 1975; Kornfield et al. 1982; Kornfield and Taylor 1983; for review see Meyer 1989 b).

Specimens of trophically polymorphic cichlids exhibit one of two types of pharyngeal jaws, possessing either strong molariform dentition and hypertrophied branchial musculature or weak papilliform dentition with less welldeveloped muscles (Meyer 1988). Morphs with intermediate morphology are seldom found (Kornfield and Taylor 1983; Liem and Kaufman 1984; Meyer 1988). These distinct intraspecific morphological differences between morphs can exceed those found between closely related taxa (e.g. the African genera Gaurochromis and Labidochromis; see Hoogerhoud 1984).

The molariform morphology adapts these fish for crushing hard prey (Liem 1973; Liem and Osse 1975; Hooger- 
houd and Barel 1978). Liem and Kaufman (1984) believe that the specialized molariform morph of Cichlasoma minckleyi has the advantage of being able to resort to a secondary food source, such as snails, during ecological bottlenecks, i.e., when primary preferred food sources are scarce. Indeed, the molariform morph of $C$. minckleyi in the field feeds more often on snails when food is limited (Smith 1982, c.f., Liem and Kaufman 1984). In the laboratory, Liem and Kaufman (1984) offered a number of different prey items to molariform and papilliform C. minckleyi. As in the field, molariform fish fed significantly more often on snails than did papilliform morphs, when food was limited. When food was abundant, however, both morphs preferred softer prey over snails. This is also true for laboratory feeding of the two trophic morphs in the trophically polymorphic Neotropical cichlid, Cichlasoma citrinellum (pers. obs.).

The pharyngeal jaw structure in $C$. citrinellum is correlated with differences in external morphology (Fig. 1, Meyer 1988). Molariform morphs have blunter, shorter snouts, larger eyes, wider heads, and deeper shorter bodies than papilliform morphs. The 'benthic' body form of molariform morphs may be adaptive for the more complex littoral habitat while the 'limnetic' elongate body form of papilliform morphs may be advantageous in open water (see also Ehlinger and Wilson 1988).

The two morphs of C. citrinellum seem to be ecologically separated through dietary differences (Meyer 1988, 1989 a). Significantly more molariform fish from Lake Jiloa, Nicaragua, fed on snails (Meyer 1989a).

The hypothesized advantages of a molariform pharyngeal jaw apparatus (e.g. Liem and Kaufman 1984) beg the question: why do not all cichlids possess molariform pharyngeal jaws? To test whether there might be costs to this morphological specialization, I tested the feeding performance of molariform and papilliform trophic morphs in the polymorphic Neotropical cichlid fish Cichlasoma citrinellum on hard- and soft-shelled snails.

\section{Materials and methods}

Cichlasoma citrinellum of both morphs and hydrobiid snails (identification, D. Lindberg), on which this species feeds, were caught in Lake Jiloa, Nicaragua in July 1987 and brought to the Department of Zoology of the University of California at Berkeley. The feeding experiments were conducted in the Fall of 1987. The jawtype of each fish was determined by inspecting the pharyngeal jaws with an othoscope. This procedure does not harm the fish. Three molariform and nine papilliform fish were used in the laboratory experiments. The means of the sizes (standard length, $\mathrm{SL}$ ) of the morphs did not differ significantly (Mo: $75 \mathrm{~mm}$; Pap: $62 \mathrm{~mm}, F$-value $=3.5, P>0.05$ ).

\section{Testing the hardness of the snail shells}

The hardness of the snails and the length-hardness relationship was assessed by crushing individual snails between the compression grips of an Instron tensometer (Model 1122). The maximum crushing force borne by each snail was then determined. Before crushing, each snail was measured along its longest longitudinal dimension. Measurements were done to the nearest $0.01 \mathrm{~mm}$ with digital calipers. Because snails are crushed by molluscivorous fish across their shor- test dimension (Wainwright 1987, 1988), the snails were placed sideways between the compression grips and crushed across their minimal dimension. Wainwright (1987) found the same snail length-hardness relationship whether snails were crushed between hard flat surfaces or between the pharyngeal jaws of the molariform labrid fish Lachnolaimus maximus which were attached to the compression grips of a tensometer.

I tested three species of snails. The first species of snail, an unidentified hydrobiid snail, is the natural prey (Meyer 1988) and was collected in Lake Jiloa, Nicaragua, where the fish originated. These snails are thick-walled, heavyshelled, and conispirally shaped. This species would not breed in the laboratory and therefore could not be used in the feeding trials.

The second soft-shelled snail tested is an undetermined species of Physa that is locally abundant in California. This species is thin-walled, conispirally shaped and has a large inflated body whorl (see also Stein et al. 1984).

The third species was the prosobranch Melanoides tuberculata. This Malaysian snail is heavy-walled with a conical shell. This species is comparable in its length-hardness relationship to the natural prey snail of $C$. citrinellum from Nicaragua. Melanoides is easily maintained and reared in captivity and was used in the feeding experiments on hard diets.

\section{Laboratory conditions}

For all experiments fish were kept singly under standard laboratory conditions in 80 liter aquaria without gravel. Fish were kept in the laboratory for three months before the experiments commenced and were well acclimated to their aquaria. During the acclimation period the fish were fed a diverse diet alternating among brineshrimp, flakefood, and pelleted fish food.

\section{Feeding experiments}

In the feeding experiments fish were not given a choice of prey, but only offered one type of prey in each of the feeding experiments.

I. Soft prey. I tested the feeding efficiency of both fish morphs on soft diets by feeding soft-shelled Physa snails to the fish. Each snail was measured before and singly introduced into a tank. During the experiment, only one snail was present in the tank at any time. I chose snails haphazardly from a holding tank to randomize the size and order of presenting snails to the test fish.

Handling time was the time (s) between engulfing of each snail and spitting out shell fragments. When fish fed on Physa they spit out shell fragments, allowing a precise measurement of handling time. I chose Physa as soft prey, because the fish swallowed other soft diets, such as brineshrimp, whole without spitting out hard fragments, which did not allow the unambiguous measurement of the handling time. I followed this procedure for, at most, ten snails per day per fish.

Satiation usually occurred before ten snails were devoured. When the fish refused to feed on a particular Physa within three minutes it was judged to be satiated. Then a smaller snail was offered; if this snail was also ignored the testing was stopped. This procedure was followed for 15 consecutive days to test for the effect of learning (experi- 
ence) on feeding performance. The time spent handling food should reflect the energetic cost of handling (Stein et al. 1984); therefore, a shorter handling time is a more efficient feeding mode, and larger snails have the highest energy return for handling time.

II. Hard prey. Feeding performance on hard prey was tested by feeding the snail Melanoides tuberculata to the fish. The experimental procedure of the feeding experiments on hard diets differed from that of the soft-prey experiment. It was not possible to measure handling time directly because snails were spit our repeatedly, repositioned between the pharyngeal jaws, and spit out again. This handling of the hard snails often took a long time (more than $30 \mathrm{~min}$ ). I, therefore, did not measure feeding efficiency in the same way as in the experiments with soft prey (s) but rather measured feeding performance (sizes of snails cracked).

I introduced 10 Melanoides of known length to each tank daily. The fish preyed successfully on a subset of these 10 snails. They cracked snails between their pharyngeal jaws and shell fragments were spit out into the tank. On the following day, and for 14 days, I collected the remaining intact snails from each tank and measured them again. Snails that were not recovered from tanks were assumed to have been cracked by the fish. This experiment allowed me to assess the sizes of hard snails that the fish were able to crack.

\section{Statistical methods}

The same fish were sampled repeatedly. Therefore, I analyzed the handling time for the soft prey experiment and the snail length for the hard prey experiment with univariate and multivariate repeated measures analysis. This analysis accounts for the repeated measures design. It provides three tests. A between-subjects test, testing for overall differences between the two jaw types. Within-subject effects (the influence of experience) are tested with a univariate repeated measures $F$-tests. The interaction effects of jaw morph and experience are tested within-subjects with a univariate repeated measures $F$-tests.

Because this analysis will exclude whole cases (fish) if data are missing from the matrix, the original data were reduced from 9 to 7 papilliform fish for the soft-prey experiment and 5 papilliform fish for the hard-prey experiment. Furthermore, only days at which all of the fish ate at least one snail could be considered, reducing the number of days to 7 for the hard-prey experiment. If more than one snail was eaten per fish and day the mean length and handling time were calculated for the hard-prey and the soft-prey experiment respectively.

\section{Results}

\section{Length-hardness relationships of snails}

For all snails the crushing force (in Newtons) required to crack the shell rose with increasing size of the snail (Fig. 2, Table 1). The hard snail used in the feeding experiment, Melanoides, is not statistically distinguishable in its lengthhardness relationship from the natural (Nicaraguan) prey species (Table 1). The soft snail Physa is significantly different (softer) in its length-hardness relationship from the hard snail Melanoides (Table 1). These results validate the choice of the two species as hard and soft diets (Fig. 2).
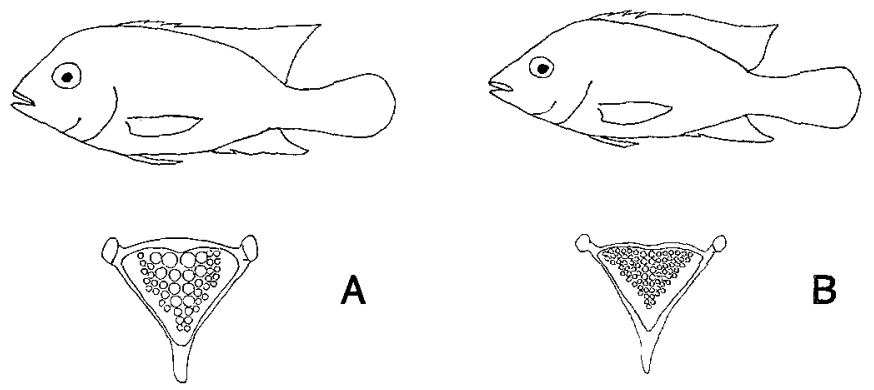

A

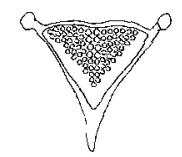

B

Fig. 1A, B. Semi-schematic drawing of the differences in body shape and pharyngeal jaw morphology in C. citrinellum. Molariform morphs (A) have a shorter, blunter snout, wider head, larger eye, deeper body than papilliform morphs (B). The pharyngeal jaws are sturdier, larger, and have larger molariform teeth in molariform morphs (A) than in papilliform morphs (B)

Table 1. Length-hardness relationship of snails. (Natural prey: Nicaragua, $N=73$ ), the hard snail (Melanoides, $N=44$ ), and the soft snail (Physa, N=50). The length of the snail was measured in $\mathrm{mm}$ and the crushing force measured in Newtons, both measurements were log-transformed for this analysis. Comparisons of length-hardness relationships were done with ANCOVAs (with the length of the snail as covariate). The homogeneity of slopes was tested prior to the comparisons; none of the slopes differed significantly. The adjusted means did not differ between the two hard snail species tested, the natural hydrobiid prey and the Melanoides. The adjusted means between the soft prey Physa and the hard prey Melanoides differed significantly. Both results justify the choice of prey

\begin{tabular}{|c|c|c|c|c|c|}
\hline & Constant & Slope & $F$-value & $P$-value & Adj. R-squ. \\
\hline \multicolumn{6}{|c|}{ Length-hardness regressions: } \\
\hline Nicaragua & -0.012 & 1.756 & 18.28 & 0.000 & 0.194 \\
\hline Melanoides & -0.150 & 1.770 & 94.82 & 0.000 & 0.686 \\
\hline Physa & -0.819 & 1.271 & 11.55 & 0.001 & 0.177 \\
\hline \multicolumn{6}{|c|}{ Comparisons of length-hardness relationships: } \\
\hline \multicolumn{6}{|c|}{ Nicaragua vs. Melanoides } \\
\hline \multirow{2}{*}{\multicolumn{3}{|c|}{$\begin{array}{l}\text { Test for homogeneity of slopes } \\
\text { Test for differences in adj. mean }\end{array}$}} & \multirow{2}{*}{\multicolumn{2}{|c|}{$\begin{array}{l}F=0.00 \\
F=2.17\end{array}$}} & $P>0.05$ \\
\hline & & & & & $P>0.05$ \\
\hline \multicolumn{6}{|c|}{ Physa vs. Melanoides } \\
\hline \multirow{2}{*}{\multicolumn{3}{|c|}{$\begin{array}{l}\text { Test for homogeneity of slopes } \\
\text { Test for differences in adj. mean }\end{array}$}} & \multirow{2}{*}{\multicolumn{2}{|c|}{$\begin{array}{l}F=3.00 \\
F=719.78\end{array}$}} & $P>0.05$ \\
\hline & & & & & $P<0.000$ \\
\hline
\end{tabular}

\section{Feeding on soft prey}

Physa were eaten readily by the fish and rarely rejected. Molariform morphs had a significantly longer handling time than did papilliform morphs, indicating that papilliform morphs feed more efficiently on soft prey than molariform morphs (molariform morphs: mean: $35.8 \mathrm{~s}$, SD: 12.21; papilliform morphs: $21.6 \mathrm{~s}$, SD: 2.95; Table 2). Within subjects experience had a weak but significant effect for both morphs (i.e. handling time decreased: $P=0.042$; Table 2). However, within subjects the combined effects of experience and jaw morphology are not significantly different (Table 2).

\section{Feeding on hard prey}

Molariform morphs of $C$. citrinellum were able to crack significantly harder snails than could the papilliform 


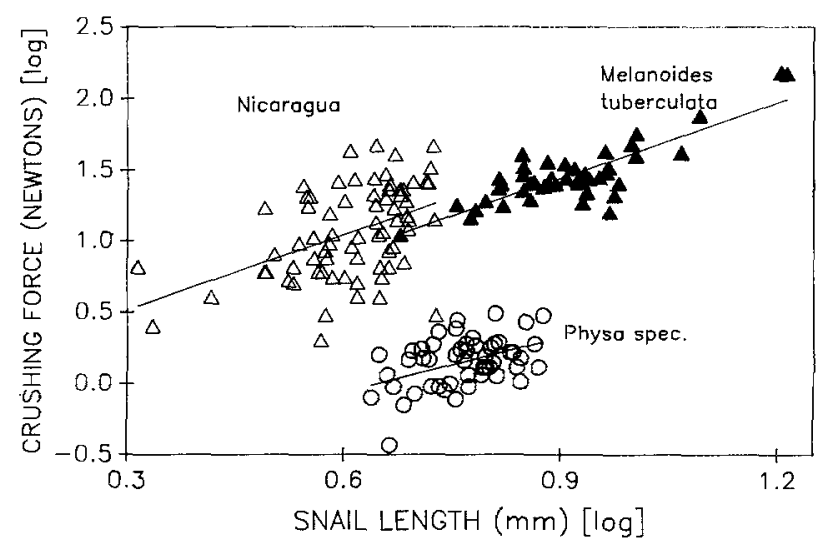

Fig. 2. Relationship of snail length and required crushing force for the three species of snails used in the experiments. Snails were measured to the nearest $0.01 \mathrm{~mm}$ and crushing force read as the maximal force required to crush the snail shell. Both measurements are log-transformed and log-transformed data are used for the analyses in Table 1. See Methods for details of the methodology and Table 1 for regression equations

Table 2. Feeding performance on the soft prey Physa. Repeated measures design with 3 molariform and 7 papilliform fish for 15 feeding experiments

\begin{tabular}{|c|c|c|c|c|c|}
\hline Source & SS & DF & MS & $F$-value & $P$-value \\
\hline \multicolumn{6}{|c|}{ Between subjects: } \\
\hline Jaw morph & 6314 & 1 & 6314 & 14.522 & 0.005 \\
\hline \multicolumn{6}{|c|}{ Individuals within morph } \\
\hline & 3478 & 8 & 434 & & \\
\hline \multicolumn{6}{|c|}{ Within subject: } \\
\hline Experience & 5383 & 14 & 384 & 1.832 & 0.042 \\
\hline \multicolumn{6}{|c|}{ Experience and jaw morph } \\
\hline & 4316 & 14 & 308 & 1.469 & 0.135 \\
\hline \multicolumn{6}{|c|}{ Experience $*$ Individual within morph } \\
\hline & 23514 & 112 & 209 & & \\
\hline
\end{tabular}

Table 3. Feeding performance on the hard prey Melanoides. Repeated measures design with 3 molariform and 5 papilliform fish for 7 feeding experiments

\begin{tabular}{|c|c|c|c|c|c|}
\hline Source & SS & DF & MS & $F$-value & $P$-value \\
\hline \multicolumn{6}{|c|}{ Between subjects effect: } \\
\hline Jaw morph & 23.5 & 1 & 23.5 & 17.932 & 0.005 \\
\hline \multicolumn{6}{|c|}{ Individuals within morph } \\
\hline & 3478 & 6 & 434 & & \\
\hline \multicolumn{6}{|c|}{ Within subject effects: } \\
\hline Experience & 18.8 & 6 & 3.13 & 8.54 & 0.000 \\
\hline \multicolumn{6}{|c|}{ Experience and morph } \\
\hline & 5.84 & 6 & 0.974 & 2.66 & 0.031 \\
\hline \multicolumn{6}{|c|}{ Experience $*$ Individual within morph } \\
\hline & 13.2 & 36 & 0.366 & & \\
\hline
\end{tabular}

morphs (molariform morph: mean: $6.67 \mathrm{~mm}$, SD: $0.99 \mathrm{~mm}$; papilliform morph: mean: $5.33 \mathrm{~mm}$, SD: $0.32 \mathrm{~mm}$; Table 3). The largest snail that was cracked by molariform fish $(9.44 \mathrm{~mm})$ required $37.6 \mathrm{~N}$ to crack; this was double the force that was needed to crack the largest snail preyed on by a papilliform fish $(6.38 \mathrm{~mm} ; 18.8 \mathrm{~N})$. The forces required to crack the mean sized snails for both morphs differed almost two-fold as well (molariform: $20.35 \mathrm{~N}$; papilliform: $13.69 \mathrm{~N}$ ).

The between-subjects effect of jaw morphs is significant, i.e., molariform fish are able to crack significantly larger snails $(P<0.005$, Table 3$)$. The ability to crack hard snails improved during the experiment and the within-subjects effects of experience are statistically significant (Table 3 ). The combined effects of jaw morph and experience, tested with a within-subjects test, was significant (Table 3 ).

\section{Discussion}

Competition for the same resources is thought to be most severe between ecologically similar species. Therefore, if competitive abilities and fitness are determined by morphology (Arnold 1983), competition should be highest among conspecifics (Schoener 1971, 1974). Hence, trophically polymorphic species that show a bimodal, rather than a normal distribution for a morphological, ecologically relevant trait provide an excellent opportunity to test models for competition and speciation (Werner 1977; Wiens 1977; Rosenzweig 1978; Seger 1985). One would predict that morphologically separated morphs ought to differ in their efficiency in feeding on diets in their respective ecological niches.

\section{Feeding efficiency and morphological specialization}

Models of optimal foraging predict that a fish should maximize the energy intake per unit time or energy expenditure, and should attempt to feed on the most profitable prey (Werner 1974; Stein et al. 1975; Slootweg 1987; Hoogerhoud $1986 \mathrm{a}, \mathrm{b}$; for recent reviews of optimal foraging in fishes see Townsend and Winfield 1985; Hart 1986). By being time-minimizers for foraging they also reduce predation risk (Werner and Hall 1988). The dry weight of snails is proportional to the energetic content of the prey and increases exponentially as a function of size (Stein et al. 1984; Hoogerhoud 1986a). Stein et al. (1984) and Hoogerhoud (1986a) showed that the ratio of energy gained per unit handling time is highest for larger snails.

The maximum size of hard prey that is available prey for $C$. citrinellum in its natural habitat is probably determined by the maximum force that can be exerted by the pharyngeal jaws and not by the overall size of the snail (see also Wainwright 1987, 1988). In another cichlid it was found that, when prey density was unlimited, prey handling in the buccal cavity was the main factor limiting prey uptake (Galis and de Jong 1988).

My study confirms the hypothesis that molariform fish are superior to papilliform morphs in their ability to feed on particularly large, hard prey. The calculated maximum force that could be exerted by molariform and papilliform fish between their pharyngeal jaws differs significantly. This difference suggests that the large size, i.e. energetically most profitable classes of snails, may not be available as prey for papilliform morphs in nature. In July of 1987 the mean size of snails found in the stomachs of molariform morphs 
of C. citrinellum from Lake Jiloa Nicaragua was $5.02 \mathrm{~mm}$. A snail of this size requires approximately $16.6 \mathrm{~N}$ to crack. Based on my laboratory experiments, papilliform fish should be able to crack only softer, smaller snails in their natural environments. Yet, hardly any snails were found in stomachs of papilliform morphs in Nicaraguan lakes (Meyer 1989a). That they feed on snails at all is probably because the length-hardness relationship is not very strong for the natural prey (Fig. 2). Therefore it might be profitable for papilliform morphs to sample among the large snails for particularly soft-shelled individuals.

\section{Cost of morphological specialization}

The performance advantage of the morphologically specialized molariform morphs allows them to take less preferred (hard) prey in nature when other prey are not available. Liem and Kaufman (1984) demonstrated in the laboratory that morphologically specialized molariform morphs of $C$. minckleyi feed on hard prey significantly more often than papilliform morphs only when prey density is low. This obvious advantage of the specialized molariform morphs poses the question why are not all cichlids trophically specialized?

This study demonstrates the potential disadvantages of morphological specialization in terms of functional morphological constraints. Morphologically generalized papilliform morphs are more efficient predators on soft prey (e.g. Physa). Papilliform morphs could potentially outcompete molariform morphs for preferred soft prey and force molariform morphs into a different habitat, where soft prey are less abundant.

Apparently morphological specialization is not a handicap in some (rare?) ecological instances. Field observations have confirmed that morphologically specialized cichlids exploit other prey items for which they do not seem to be morphologically adapted if those alternative prey become superabundant (Katunzi 1983; McKaye and Marsh 1983).

Smith (1987) found in a polymorphic species of African finch a similar trade-off of morphological specialization between large-billed and small-billed forms when feeding on hard and soft seeds (Smith 1987). He finds a correlation between the occurrence of particular morphs and the hardness of seeds on which they feed, and believes that the trophic polymorphism is maintained by strong seasonality of food resources (Smith, unpublished work).

The abundance of soft and hard prey may determine the abundance of the morphs. This hypothesis is supported by my data: the proportion of molariform morphs among populations of Cichlasoma citrinellum correlates with the abundance of snails in the lakes of Nicaragua; e.g., no snails or molariform morphs are found in Lake Masaya, Nicaragua (Meyer 1988). The frequency with which snails are eaten varies between years and seasons, suggesting high seasonality of prey abundance and environmental fluctuations (unpublished work). The seasonal fluctuations of environmental conditions could perpetuate the coexistence of both morphs and might prevent the competitive exclusion and eventual extinction of either morph.

Acknowledgements. M. Conboy from Harvard University helped during the 1987 field collection in Nicaragua. M. Koehl generously allowed the use of her Instron apparatus and D. Pentcheff assisted during the snail cracking. S. Allison, E. Grosholz, S. Naeem, T.
Smith, and K. Swanson provided constructive, thoughtful criticism of the manuscript. The members of my Ph.D. thesis committee G.W. Barlow, W.P. Sousa, M.H. Wake and A.C. Wilson were especially helpful and full of advice. A pilot study was conducted with the help of L. Safram and M. Rothberg while I was a Visiting Scholar at the Museum of Comparative Zoology at Harvard University; I thank K.F. Liem for his support during that time. Travel to Central America and museum collections was funded through a Noyes grant from the Organization for Tropical Studies, a travel award from the Center for Latin American Studies at the University of California at Berkeley, a Raney Award from the American Society of Ichthyologists and Herpetologists, and an Ernst Mayr Award from the Museum of Comparative Zoology at Harvard University. Other support came from Sigma Xi, the American Cichlid Association, and the Chancellor's Patent Fund from the University of California at Berkeley. Fellowships were granted from the German and the American Fulbright Commissions and the University of California at Berkeley. G. Barlow provided advice and support through NIH grant 18612; his work and that of his previous students significantly helped in the conduct of this study. IMPESCA and ENMAR in Nicaragua granted permits; their officers, Sergio Martinez and Nussli Ruiz, helped in many ways.

\section{References}

Arnold SJ (1983) Morphology, performance, and fitness. Am Zool $23: 347-361$

Barel CDN (1983) Towards a constructional morphology of cichlid fishes (Teleostei, Perciformes). Neth J Zool 3:357-424

Ehlinger TJ, Wilson DS (1988) Complex foraging polymorphism in the bluegill sunfish. Proc Natl Acad Sci USA 85:1878-1882

Galis F, de Jong PW (1988) Optimal foraging and ontogeny; food selection by Haploplochromis piceatus. Oecologia 75:175-184

Gatz JA Jr (1979) Community organization in fishes as indicated by morphological features. Ecology 60:711-718

Grant PR (1986) Ecology and evolution of Darwin's Finches. Princeton University Press, Princeton

Greenwood PH (1965) Environmental effects on the pharyngeal mill of a cichlid fish, Astatoreochromis alluaudi and their taxonomic implications. Proc Linn Soc Lond 176:1-10

Hart PJB (1986) Foraging in teleost fishes. In: Pitcher TJ (ed) The behaviour of teleost fishes. Croom Helm, London, pp $211-236$

Hoogerhoud RJC (1984) A taxonomic reconsideration of the haplochromine genera Gaurochromis Greenwood, 1980 and Labidochromis Regan, 1920 (Pisces, Cichlidae). Neth J Zool 34:539-565

Hoogerhoud RJC (1986a) Ecological morphology of some cichlid fishes. Ph.D. thesis, Leiden, The Netherlands

Hoogerhoud RJC (1986b) Taxonomic and ecological aspects of morphological plasticity in molluscivorous Haplochromines (Pisces, Cichlidae). Ann Mus Roy Afr Centr Sc Zool 251:131-134

Hoogerhoud RJC, Barel CDN (1978) Integrated morphological adaptation in piscivorous and mollusc-crushing Haplochromis species. Osse JWN (ed) Adaptation. Proc Zodiac Symp on Adaptation. Wageningen, The Netherlands, pp 52-56

Hoogerhoud RJC, Witte F, Barel CDN (1983) The ecological differentiation of two closely resembling Haplochromis species from Lake Victoria ( $H$. in is and $H$. hiatus; Pisces, Cichlidae). Neth J Zool 33:283-305

Katunzi EFB (1983) Seasonal variation in the food of a molluscivorous cichlid Haplichromis sauvagei Pfeffer 1896. Neth J Zool $34: 337-342$

Kaufman LS, Liem KF (1982) Fishes of the suborder Labroidei (Pisces: Perciformes): Phylogeny, ecology and evolutionary significance. Breviora 472:1-19

Keast A, Webb D (1966) Mouth and body form relative to feeding ecology in the fish fauna of a small lake, Lake Opinicon, Ontario. J Fish Res Bd Can 23:1845-1874

Kornfield IL, Smith DC, Gagnon PS, Taylor JN (1982) The cichlid 
fish of Cuatro Cienegas Mexico: direct evidence of conspecificity among distinct trophic morphs. Evolution 36:658-664

Kornfield IL, Taylor IN (1983) A new species of polymorphic fish, Cichlasoma minckleyi from Cuatro Cienegas, Mexico (Teleostei: Cichlidae). Proc Biol Soc Wash 96:253-269

Liem KF (1973) Evolutionary strategies and morphological innovations: cichlid pharyngeal jaws. Syst Zool 22:425-441

Liem KF (1984) Functional versatility, speciation and niche overlap: Are fishes different? In: Meyers DG, Strickler JR (eds) Trophic Interactions within Aquatic Ecosystems. AAAS Selected Symposium 85, pp 269-305

Liem KF, Kaufman LS (1984) Intraspecific macroevolution: functional biology of the polymorphic cichlid species Cichlasoma minckleyi. In: Echelle AA, Kornfield I (eds) Evolution of Fish Species Flocks. Univ. Maine Press, Orono, pp 203-215

Liem KF, Osse JW (1975) Biological versatility, evolution, and food resource exploitation in African cichlids. Am Zool $15: 427-454$

McKaye KR, Marsch A (1983) Food switching by two specialized algae-scraping cichlid fishes in Lake Malawi, Africa. Oecologia $56: 245-248$

Meyer A (1987) Phenotypic plasticity and heterochrony in Cichlasoma managuense (Pisces, Cichlidae) and their implications for speciation in cichlid fishes. Evolution 41:1357-1369

Meyer A (1988) Plasticity in morphology and performance in the trophically polymorphic cichlid fish Cichlasoma citrinellum. $\mathrm{Ph}$.D. thesis, University of California, Berkeley

Meyer A (1989a) Ecological and evolutionary aspects of a trophic polymorphism in the Neotropical cichlid Cichlasoma citrinellum (Pisces, Cichlidae). Biol J Linn Soc (in press)

Meyer A (1989b) Trophic polymorphisms in cichlid fish: do they represent intermediate steps during sympatric speciation and explain their rapid adaptive radiation? In: Schroder JH (ed) New trends in ichthyology. Paul Parey, Berlin (in press)

Rosenzweig ML (1978) Competitive speciation. Biol J Linn Soc $10: 275-289$

Sage RD, Selander RK (1975) Trophic radiation through polymorphism in cichlid fishes. Proc Nat Acad Sci USA 72:4669 4673

Schoener TW (1971) Theory of feeding strategies. Ann Rev Ecol Syst $2: 369-404$

Schoener TW (1974) Resource partitioning in ecological communities. Science 185:27-39

Seger J (1985) Intraspecific competition as a cause of sympatric speciation. In: Greenwood PJ, Harvey PH, Slatkin M (eds)
Evolution, Essays in Honour of John Maynard Smith. Cambridge Univ. Press, Cambridge, pp 43-53

Slootweg R (1987) Prey selection by molluscivorous cichlids foraging on a schistosomiasis vector snail, Biomphalaria glabrata. Oecologia 74:193-202

Smith DC (1982) Trophic ecology of the cichlid morphs of Cuatro Cienegas, Mexico. MS thesis, University of Maine, Orono

Smith TB (1987) Bill size polymorphism and intraspecific niche utilization in an African finch. Nature 329:717-719

Stein RA, Kitchell JF, Knezevic B (1975) Selective predation by carp (Cyprinus carpio L.) on benthic molluses in Skadar Lake, Yugoslavia. J Fish Biol 1975:391-399

Stein RA, Gosse-Goodman C, Marschall EA (1984) Using time and energetic measures of cost in estimating prey value for fish predators. Ecology 65:702-715

Townsend CR, Winfield If (1984) The application of optimal foraging theory to feeding behaviour in fish. In: Tyler $\mathrm{P}$, Calow $P$ (eds) Fish energetics new perspectives. Croom Helm, London, pp 67-98

Van Oijen MJP (1982) Ecological differentiation among the piscivorous haplochromine cichlids of Lake Victoria (East Africa). Neth J Zool 32:336-362

Van Valen L (1965) Morphological variation and the width of the ecological niche. Am Nat 94:377-390

Wainwright PC (1987) Biomechanical limits to ecological performance: mollusc crushing by the Caribbean hogfish, Lachnolaimus maximus (Labridae). J Zool Lond 213:283-297

Wainwright PC (1988) Morphology and ecology: the functional basis of feeding constraints in Caribbean labrid fishes. Ecology $69: 635-645$

Werner EE (1974) The fish size, prey size, handling time relation in several sunfishes and some implications. J Fish Res Bd Can $31: 1531-1536$

Werner EE (1977) Species packing and niche complementarity in three sunfishes. Am Nat 111:553-578

Werner EE, Hall DJ (1988) Ontogenetic habitat shifts in bluegill: the foraging rate-predation risk trade-off. Ecology $69: 1352-1366$

Wiens JA (1977) On competition and variable environments. Am Sci 65:590-597

Received December 15, 1988 